\title{
The validation of a functional, isolated pig bladder model for physiological experimentation
}

\author{
Brian A. Parsons ${ }^{1,2}$, Marcus J. Drake ${ }^{1,2}{ }^{*}$,Andrew Gammie ${ }^{1}$, Christopher H. Fry ${ }^{3}$ and Bahareh Vahabi ${ }^{1,4}$ \\ ${ }^{1}$ Southmead Hospital, Bristol Urological Institute, Bristol, UK \\ ${ }^{2}$ Faculty of Medicine and Dentistry, University of Bristol, Bristol, UK \\ ${ }^{3}$ Postgraduate Medical School, University of Surrey, Guildford, UK \\ ${ }^{4}$ Department of Applied Sciences, University of the West of England, Bristol, UK
}

Edited by:

Elizabeth Burcher, University of New

South Wales, Australia

Reviewed by:

Elizabeth Burcher, University of New

South Wales, Australia

Robert Evan Hurst, Oklahoma

University Health Sciences Center,

USA

Kate Hilda Moore, St. George

Hospital, Australia

Medardo Hernández, Universidad

Complutense de Madrid, Spain

*Correspondence:

Marcus J. Drake, Southmead

Hospital, Bristol Urological Institute,

Bristol BS10 5NB, UK.

e-mail: marcus_drake@bui.ac.uk
Characterizing the integrative physiology of the bladder requires whole organ preparations. The purpose of this study was to validate an isolated large animal (pig) bladder preparation, through arterial and intravesical drug administration, intravesical pressure recording, and filming of surface micromotions. Female pig bladders were obtained from the local abattoir and arterially perfused in vitro. Arterial and intravesical pressures were recorded at varying volumes. Bladder viability was assessed histologically and by monitoring inflow and outflow pH. Arterial drug administration employed boluses introduced into the perfusate. Intravesical administration involved slow instillation and a prolonged dwell-time. Surface micromotions were recorded by filming the separation of surface markers concurrently with intravesical pressure measurement. Adequate perfusion to all bladder layers was achieved for up to $8 \mathrm{~h}$; there was no structural deterioration nor alteration in inflow and effluent perfusate $\mathrm{pH}$. Arterial drug administration (carbachol and potassium chloride) showed consistent dose-dependent responses. Localized movements (micromotions) occurred over the bladder surface, with variable correlation with fluctuations of intravesical pressure. The isolated pig bladder is a valid approach to study integrative bladder physiology. It remains viable when perfused in vitro, responds to different routes of drug administration and provides a model to correlate movements of the bladder wall directly to variation of intravesical pressure.

Keywords: pig, whole bladder, spontaneous activity, micromotions, intravesical pressure

\section{INTRODUCTION}

The primary physiological functions of the urinary bladder are the storage of urine at relatively low intravesical pressure and its expulsion (voiding) at appropriate times. Within the bladder wall are various cell types whose complex interactions determine its functional and mechanical properties. The contractile properties of the bladder are controlled by descending central inhibition and activation which overlay a complex autonomous (spontaneous) activity. The latter is most readily characterized when the bladder is freed from central control (Van Duyl, 1985; Coolsaet et al., 1993; Sugaya and de Groat, 2000; Drake et al., 2003a,b; Gevaert et al., 2009). It is manifest as localized contractions and stretches of the bladder wall which can be enhanced by increases in intravesical volume or by applying a muscarinic receptor agonist at low concentrations (Gillespie et al., 2003; Lagou et al., 2004). Furthermore, spontaneous contractions contribute to the overall contractile properties of the bladder under physiological and pathological conditions such as the overactive bladder (Kinder and Mundy, 1987).

Much of our knowledge of spontaneous bladder activity has come from in vitro research using muscle strips and isolated cells that can yield information about cellular pathways and local intracellular interactions (Oh et al., 1999; Yamanishi et al., 2000; Hashitani et al., 2001; Buckner et al., 2002). However, autonomous pressure changes in the whole bladder are also dependent on its geometrical properties and interactions between different tissue layers. Thus, to interpret findings from small isolated preparations requires them to be validated with whole organ preparations. To date most of this work has used bladders from small rodents maintained in physiological saline environments (Drake et al., 2003a; Gillespie et al., 2003; Fabiyi and Brading, 2006; Buyuknacar et al., 2010). Extrapolating findings generated using small laboratory animals to the physiology of urine storage and voiding in large animals and the clinical context is difficult, and requires validation as additional issues have to be reconciled such as: differences in the base-line physiological properties of larger bladders and experimental considerations (adequate tissue perfusion and environmental control). Studies have evaluated the urodynamic properties of pig in vivo, demonstrating comparable urodynamic (Sibley, 1984; Crowe and Burnstock, 1989; Mills et al., 2000b; Moore and Brading, 2007) and structural (Dixon and Gosling, 1983; Teufl et al., 1997) characteristics to humans, and potential clinical relevance. A novel extracorporeal perfusion model using isolated pig urinary bladder has been used to study its contractile properties (Dittrich et al., 2007). The purpose of the present study was to further validate the technique, to develop it by including arterial drug administration and micromotion filming, and to evaluate its potential for study of the integrative physiology of the large animal bladder. 


\section{MATERIALS AND METHODS PIG BLADDER RETRIEVAL}

Female pig (Sus scrofa domestica, $\sim 6$ months old) bladders were obtained from the local abattoir immediately post mortem. At the abattoir, the abdomen of the animal was opened using a longitudinal midline incision extending from the jugular notch to the pubic symphysis. The distal abdominal aorta and the branches supplying the bladder were identified and carefully dissected free. The bladder and associated vasculature were then excised and perfused with ice-cold Krebs' solution at $4^{\circ} \mathrm{C}$ until all blood was drained from the organ. The warm ischemic time between killing the animal and bladder retrieval did not exceed $35 \mathrm{~min}$ (mean $30 \pm 5 \mathrm{~min}$ ). The bladder was then placed in ice-cold physiological buffer and transported to the laboratory. The distal aorta was cannulated using a 14 gage needle (BD Vialon ${ }^{\mathrm{TM}}$ ) and redundant branches were ligated. Ethical approval was not required as the organs were obtained from animals killed for human consumption.

\section{PERFUSION SYSTEM}

Using a peristaltic pump (Watson-Marlow Pumps Group, UK), the bladder was perfused via the aortic catheter at a constant rate of $10 \mathrm{ml} / \mathrm{min}$ with freshly made Krebs' solution (mM: NaCl, 118.3; $\mathrm{NaHCO}_{3}, 24.9 ; \mathrm{KCl}, 4.7 ; \mathrm{MgSO}_{4}, 1.15 ; \mathrm{KH}_{2} \mathrm{PO}_{4}, 1.15 ; \mathrm{CaCl}_{2} 1.9$; D-glucose, 11.7 , gassed with $95 \% \mathrm{O}_{2} / 5 \% \mathrm{CO}_{2}$, $\mathrm{pH} 7.38 \pm 0.01$, $36 \pm 1^{\circ} \mathrm{C}$ ). The optimum pump perfusion rate for the experimental protocol was determined by measuring the weights of the experimental bladders before and after the perfusion period. A small degree of edema was to be expected as the Kreb's solution used to perfuse the ex vivo bladders does not have a significant oncotic pressure. In early experiments as the whole bladder apparatus was being developed, we found that perfusion rates of $30 \mathrm{ml} / \mathrm{min}$ or above led to excessive edema. Below this rate, the weight increase was less than $20 \%$ over the 8 -h perfusion period, so we did not consider it necessary to increase the oncotic pressure of the perfusion solution with albumin or dextran. The $10 \mathrm{ml} / \mathrm{min}$ perfusion rate we settled upon gave a good balance of sustained viability and minimal edema, and is in keeping with the mean peak bladder blood flows measured in male human bladders using an endoscopic laser Doppler probe (Kershen et al., 2002). The perfused bladder was maintained at $36 \pm 1^{\circ} \mathrm{C}$ in a specially manufactured doublejacketed glass organ bath (Cambridge Glassblowing, UK). The perfusion medium was not re-circulated to ensure that the bladder received optimal levels of nutrients and oxygenation, whilst preventing the build up of metabolic end products. Intra-arterial perfusion pressure was monitored (below).

\section{INTRAVESICAL AND ARTERIAL PRESSURE MEASUREMENT}

For intravesical pressure, a $6 \mathrm{Ch}$ urodynamic double-lumen catheter (Mediplus, UK) was inserted into the bladder via the left ureter and secured with a vicryl ligature. The right ureter was tied off to ensure isovolumetric conditions. A $14 \mathrm{Ch}$ Foley catheter (Bard, UK) was also passed into the bladder through the urethra and secured in place to aid emptying and filling at $50 \mathrm{ml} / \mathrm{min}$. To achieve different bladder volumes, the lumen was filled with pre-warmed Krebs' solution and allowed to equilibrate for $10 \mathrm{~min}$. A 16-gage catheter (Portex ${ }^{\circledR}$, Smiths Medical International Ltd., USA) was placed into the distal aorta via one of its branches for arterial pressure measurement. The perfusion pressure to maintain a constant rate of flow through the vascular tree was monitored to represent arterial pressure. The fluid-filled catheters were connected to external pressure transducers (MX960, Medex Inc., UK) which were fixed at a pre-determined reference height and zeroed to atmosphere prior to experimentation. This ensured that pressure measurements from all experiments were subject to the same hydrostatic component. Once catheterised, pressure recording was commenced immediately, but the bladder was left to equilibrate for $30 \mathrm{~min}$ before any manipulations. A Powerlab data acquisition system (AD Instruments, UK) was used to record continuously the pressures generated, and "Chart 7.0" software was used to analyze the acquired data.

\section{ASSESSMENT OF BLADDER VIABILITY Histological assessment}

Biopsies were taken from the bladder dome after $8 \mathrm{~h}$ of perfusion. The samples were fixed in $4 \%$ buffered formalin and then embedded in paraffin blocks. Sections $(10 \mu \mathrm{m})$ were mounted on glass slides, stained with haematoxylin and eosin (H\&E) and then examined by a histopathologist using light microscopy to assess for the presence of autolysis. Photomicrographs of representative samples were taken using a digital color camera system (Olympus, UK). At the end of each experiment, the quality of organ perfusion achieved was assessed by injecting methylene blue through the aortic cannula and visually assessing the extent and depth of staining of the bladder wall.

\section{Pharmacological viability}

The $\mathrm{pH}$ of the perfusate before and after passage through the organ was sampled at $1 \mathrm{~h}$ intervals to determine if there were significant changes suggestive of tissue ischemia. To determine if the perfusion system was able to preserve the isolated bladder in a functional condition, the cholinergic agonist carbachol (Sigma, $\mathrm{UK})$ and potassium chloride $(\mathrm{KCl})$ were administered using both intra-arterial and intravesical routes.

Arterial drug administration. Drugs were administered as $1 \mathrm{ml}$ boluses in the perfusate via the arterial cannula (as described by Dittrich et al., 2007). Increasing concentrations of carbachol $\left(1 \times 10^{-6}\right.$ to $\left.3 \times 10^{-3} \mathrm{M}\right)$ and $\mathrm{KCl}\left(20-200 \times 10^{-3} \mathrm{M}\right)$ were given to produce dose response curves. A $20 \mathrm{~min}$ washout period was allowed between doses.

Intravesical drug administration. We elected not to fill organs from empty, to reduce the confounding influence of acute distension, so bladders were filled with $100 \mathrm{ml}$ of Krebs solution and allowed to equilibrate for $20 \mathrm{~min}$. The need to achieve rapid distribution of the pharmacological agent throughout the intravesical compartment required a sufficient volume to achieve mixing into the volume already present, so $50 \mathrm{ml}$ of Krebs' solution containing the drug were then instilled into the bladder to achieve the overall intravesical volume concentration required (carbachol: $1 \times 10^{-6}$ to $3 \times 10^{-3} \mathrm{M}$ and $\mathrm{KCl} 20-200 \times 10^{-3} \mathrm{M}$ ). The bladder was equilibrated with each concentration of carbachol or $\mathrm{KCl}$ for $20 \mathrm{~min}$. Removal of pharmacological agents was undertaken by using repeated bladder washouts for $20 \mathrm{~min}$. For control experiments, carbachol and $\mathrm{KCl}$ were omitted from the $50 \mathrm{ml}$ instillation. 


\section{ASSESSMENT OF SPONTANEOUS ACTIVITY}

To demonstrate the effect of intravesical volume and bladder wall stretch on spontaneous activity, bladders were filled with $50 \mathrm{ml}$ increments from an initial volume of $150 \mathrm{ml}$ (average minimum volume of urine retrieved from bladders after killing) to a maximum volume of $450 \mathrm{ml}$ (average maximum volume of urine retrieved from bladders after killing). These volumes are in keeping with reported pig bladder volumes from previous studies (Sibley, 1985). To evaluate how volume protocols affect spontaneous activity, a comparison was made between bladders completely emptied and refilled to $150 \mathrm{ml}$ with fresh Krebs versus bladders drained down to that volume after prior filling to $450 \mathrm{ml}$. The changes in base-line intravesical pressure and the amplitude and frequency of spontaneous activity were recorded at each volume.

\section{ASSESSMENT OF BLADDER WALL MOVEMENTS}

From an overhead view of the organ bath, a camera (30FP7 Microsoft, UK) connected to the Powerlab data acquisition system (AD Instruments, UK) was used to film bladder wall movements. The movements in separate regions were assessed by measuring variation in separation of optical features (applied carbon particles) on the bladder surface, akin to a method described previously (Gillespie et al., 2003). The distance between pairs of carbon particles at low $(150 \mathrm{ml})$ bladder volumes were measured. Synchronous variation in separation of multiple points in various regions of the bladder were assessed with analysis software (Labview, National Instruments, Austin, TX, USA) and correlated with the pressure fluctuations for the same time period.

\section{DATA ANALYSIS}

Changes of intravesical pressure in response to intra-arterial carbachol or $\mathrm{KCl}$ administration were plotted as a percentage of the maximum increase for each concentration response curve (CRC). Individual $\mathrm{EC}_{50}$ values (molar concentrations producing half maximal response) were determined by non-linear regression curve fitting of CRCs using GraphPad "Prism" (San Diego, CA, USA) software; the mean $\mathrm{EC}_{50} \pm \mathrm{SEM}$ were calculated.

The amplitude and frequency of spontaneous contractions were assessed at different volumes of bladder filling and were compared statistically with values obtained at $150 \mathrm{ml}$ using repeated measure ANOVA followed by Dunnett's post hoc test. The same analysis was undertaken for the basal intravesical pressure at the different bladder volumes. All data are presented as mean \pm SEM and $\mathrm{n}$ represents the number of bladders used. The video recording experiments are primarily descriptive and were not amenable to statistical analysis.

\section{RESULTS \\ ASSESSMENT OF BLADDER VIABILITY \\ Tissue perfusion}

Intra-arterial administration of methylene blue resulted in successful staining of the serosa, detrusor, and urothelium of the entire organ (Figures 1A,B), indicating adequacy of perfusion.

\section{Histological assessment}

Light microscopic examination of $\mathrm{H} \& \mathrm{E}$ stained bladder biopsies $(n=6)$ taken after $8 \mathrm{~h}$ of perfusion demonstrated wellpreserved tissue architecture with no evidence of autolysis or

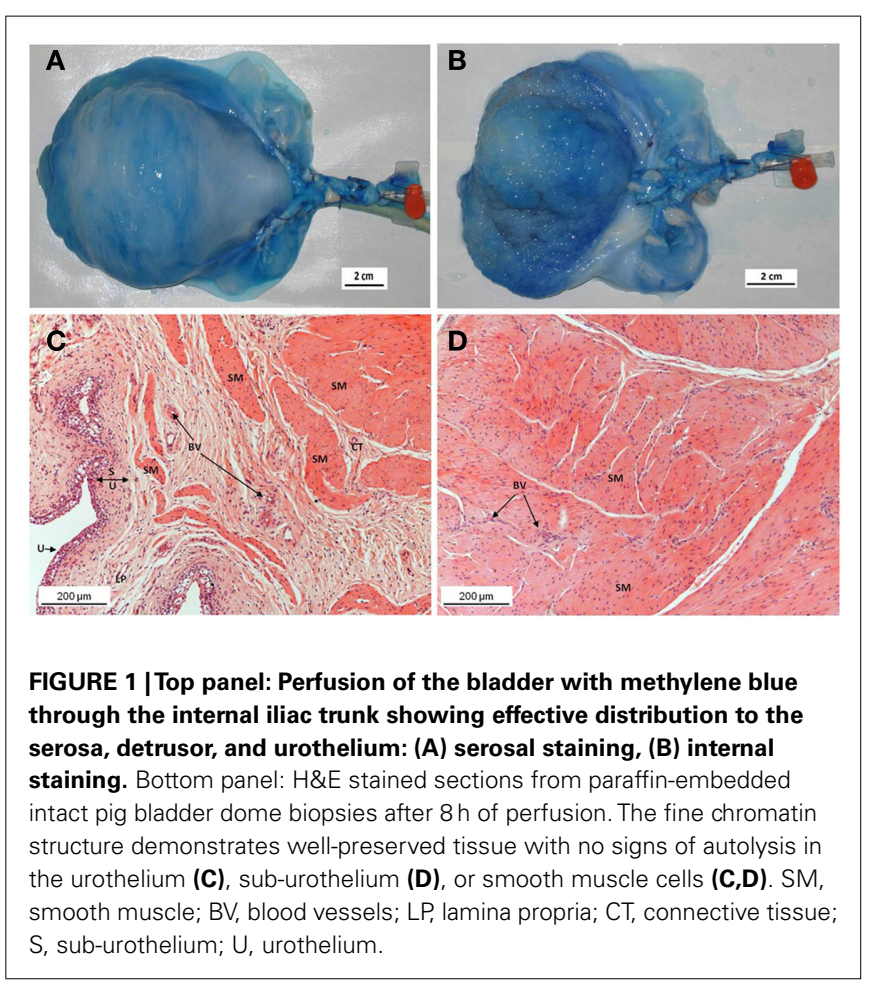

necrosis (Figures 1C,D). The urothelial layer was preserved in samples taken at the end of the perfusion period, with an intact urothelium and no separation of the mucosa and muscle layers (Figures 1C,D). Muscle bundles were well-preserved with little evidence of edema, except in some of the bladders beyond $10 \mathrm{~h}$ of experimentation time; therefore the perfusion period was kept to a maximum of $8 \mathrm{~h}$.

\section{Biochemical viability}

The $\mathrm{pH}$ of the perfusate at bladder inflow and outflow showed no significant changes over the course of the experiment (inflow $\mathrm{pH}=7.38 \pm 0.01$ versus outflow $\mathrm{pH}=7.44 \pm 0.01, n=6$, Student's paired $t$-test: $p>0.05$ ).

\section{Arterial drug administration}

During the 8 -h perfusion period, the bladders produced consistent contractile responses to arterial boluses of carbachol and $\mathrm{KCl}$. After the period of equilibration, $1 \times 10^{-5} \mathrm{M}$ carbachol generated a pressure rise of $5.2 \pm 2.0 \mathrm{cmH}_{2} \mathrm{O}$ and this was not significantly different $(p>0.05)$ from the response elicited at the end of the perfusion period $\left(6.1 \pm 2.6 \mathrm{cmH}_{2} \mathrm{O}, n=6\right)$, demonstrating the stability of the responses. Carbachol produced concentrationdependent rises in intravesical pressure (Figure 2A). Basal arterial pressure remained stable throughout the experimental period. A gradual rise in perfusion pressure was noted with increasing bladder volumes, but these reverted to basal levels on bladder emptying. The increase in perfusion pressure measured between empty and $450 \mathrm{ml}$ bladder capacity was $10.4 \pm 2.1 \mathrm{cmH}_{2} \mathrm{O}$. There were also contraction-dependent transient increases in arterial pressure occurring synchronously with agonist-induced changes in intravesical pressure under isovolumetric conditions (Figure 2B). Such 


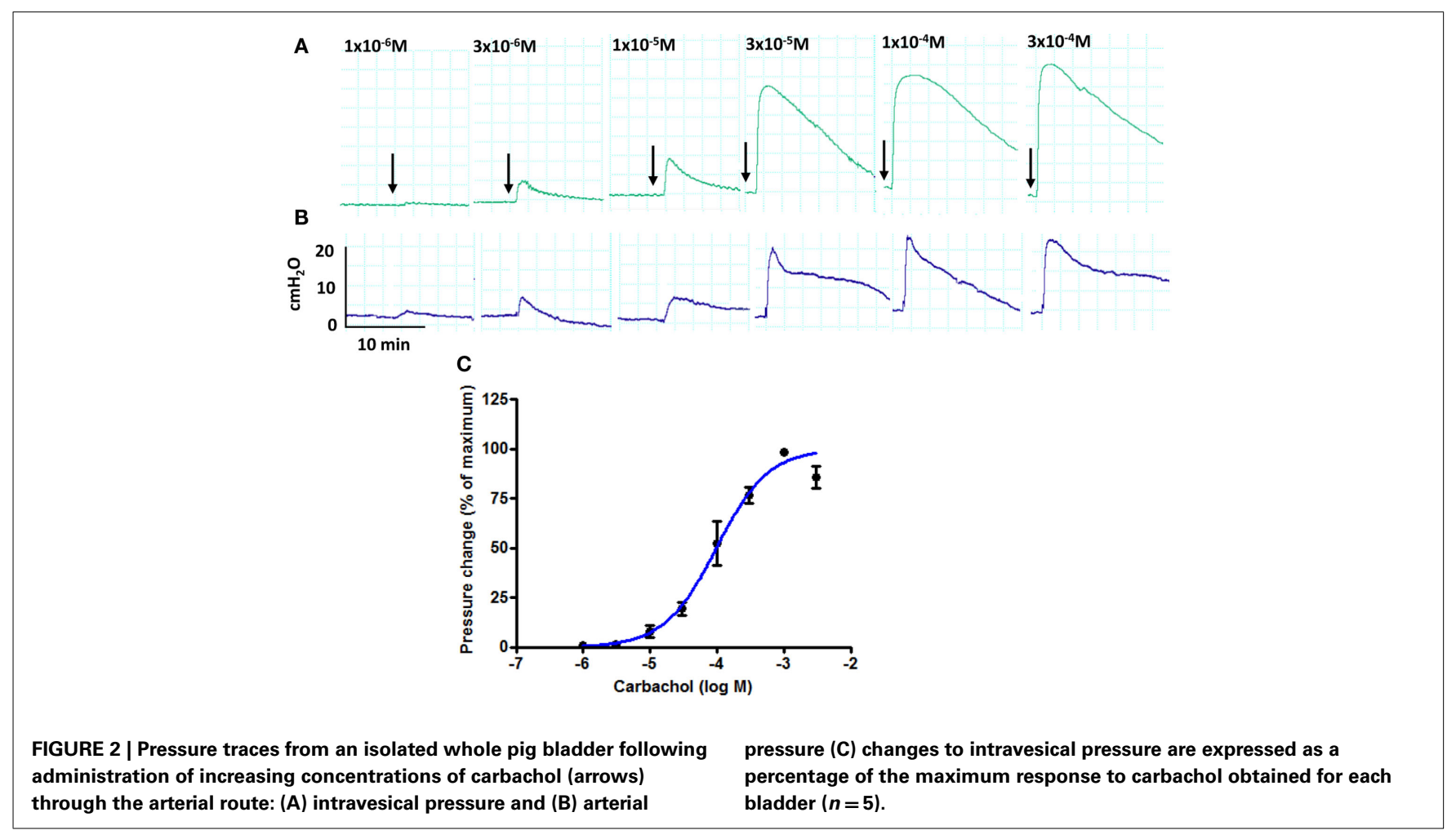

increases in perfusion pressure did not occur when the bladders were allowed to empty during contraction, indicating an increase of vascular resistance due to the restriction of flow through blood vessels during contraction. The maximum response to carbachol was $63.2 \pm 3.6 \mathrm{cmH}_{2} \mathrm{O}$ at $1 \times 10^{-3} \mathrm{M}$ and the $\mathrm{EC}_{50}$ was $96.7 \pm 22.7 \times 10^{-6} \mathrm{M}$ (Figure $2 \mathrm{C}$ ). High-K solutions $(\mathrm{KCl})$ also produced concentration-dependent increases in intravesical pressure. The maximum response to $\mathrm{KCl}$ was $21.0 \pm 7.4 \mathrm{cmH}_{2} \mathrm{O}$ and the $\mathrm{EC}_{50}$ was $136.4 \pm 6.6 \times 10^{-3} \mathrm{M}$. There were also contractiondependent increases of arterial pressure, as with the carbachol contractions (data not shown).

\section{Intravesical drug administration}

Due to the acute effects of varying intravesical volume, we elected to deliver boluses of carbachol into an already part-filled bladder $(100 \mathrm{ml})$, rather than administer entire volumes into a completely empty bladder. Figure 3A shows that infusion of a further $50 \mathrm{ml}$ Krebs solution generated a small step change in pressure. Delivery of a similar bolus containing carbachol at the highest concentration used $\left(3 \times 10^{-3} \mathrm{M}\right)$ generated not just a volume related step change but also a subsequent ongoing contraction with augmented spontaneous pressure variations, Figure 3B. The effect of intravesical carbachol was reversible after washout. In contrast to carbachol, $\mathrm{KCl}$ did not stimulate bladder contractions at any concentration (data not shown).

\section{EFFECT OF BLADDER VOLUME ON INTRAVESICAL BASE-LINE PRESSURE AND PHASIC CONTRACTIONS}

After the $30 \mathrm{~min}$ period of equilibration, all bladders developed basal phasic contractions once filling commenced. Representative traces of spontaneous contractions at low and high bladder

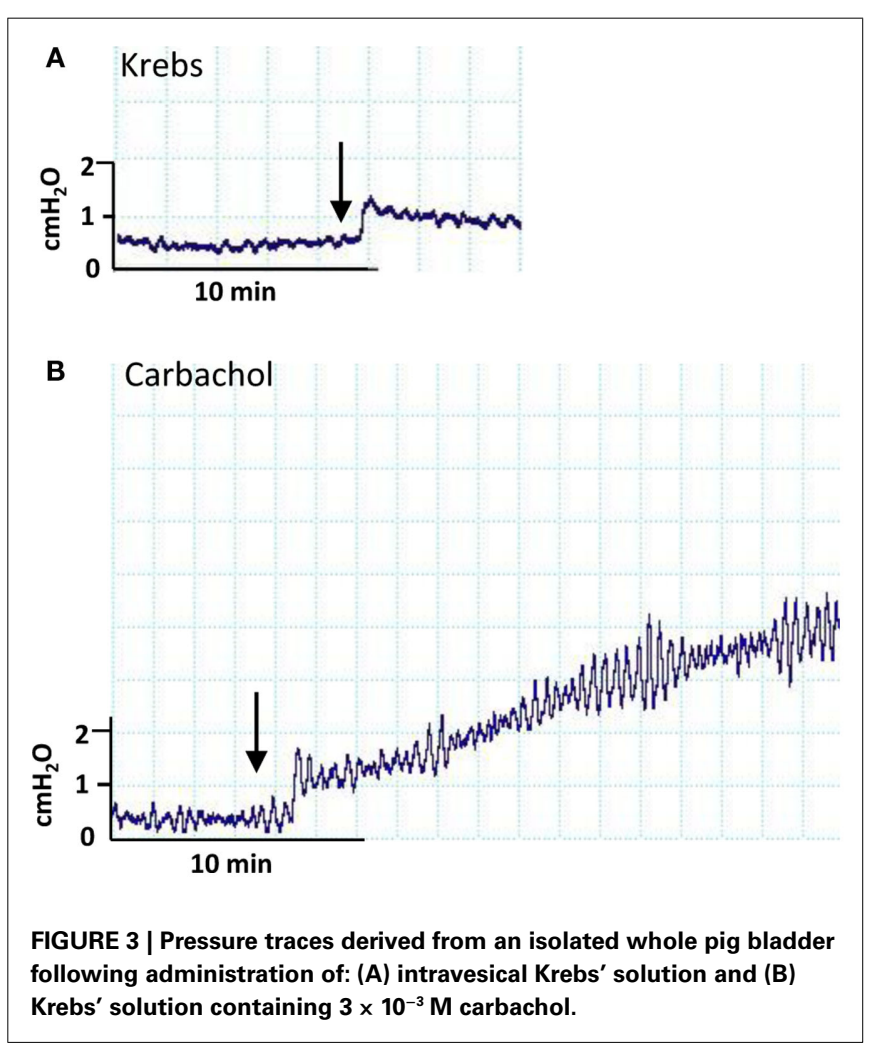

volumes are shown in Figure 4A. At steady-state after filling to a new volume, spontaneous contractions were counted for $5 \mathrm{~min}$ intervals and the following were recorded: frequency, base-line 
pressure and average contraction amplitude. The frequency of contraction was unaffected by filling to different volumes; values were $7.6 \pm 0.6 / \mathrm{min}(n=6)$ at $150 \mathrm{ml}$ and $8.8 \pm 0.3 / \mathrm{min}(n=7)$ at $450 \mathrm{ml}(p>0.05)$ (Figure 4D). Figures 4B,C show the variation of base-line pressure and mean spontaneous contraction amplitude between 150 and $450 \mathrm{ml}$ intravesical volume. Base-line pressure increased significantly from $1.6 \pm 0.9 \mathrm{cmH}_{2} \mathrm{O}(n=6)$ at $150 \mathrm{ml}$ to $3.7 \pm 1.3 \mathrm{cmH}_{2} \mathrm{O}(n=6)$ at $450 \mathrm{ml}(p<0.01)$, representing a compliance of $142.9 \mathrm{ml} / \mathrm{cmH}_{2} \mathrm{O}$. The amplitude of spontaneous contractions increased significantly from $0.4 \pm 0.1 \mathrm{cmH}_{2} \mathrm{O}(n=6)$ at $150 \mathrm{ml}$ to $1.4 \pm 0.3 \mathrm{cmH}_{2} \mathrm{O}(n=6)$ at $450 \mathrm{ml}(p<0.01)$.

When the bladder was drained completely after the filling protocol and then refilled to $150 \mathrm{ml}$ with fresh Krebs (150E), the base-line and spontaneous contraction amplitudes returned to their pre-filling values (Figures 4B,C). However, when the bladder volume was merely drained back down to $150 \mathrm{ml}$ (150D) the amplitude of spontaneous contractions remained significantly $(p<0.01)$ elevated compared to the initial $150 \mathrm{ml}$ volume (Figure 4C). This was not the case for the base-line pressure (Figure 4B). As seen during filling, the frequency of spontaneous contractions was unaffected by these emptying maneuvers (Figure 4D). Arterial pressure rose throughout the filling protocol and returned to base-line on emptying back to $150 \mathrm{ml}$.

\section{ASSESSMENT OF MICROMOTIONS}

Video filming in the absence of any pharmacological stimulus revealed the presence of localized wall movements (micromotions) throughout the bladder surface occurring at a frequency similar to the recorded pressure fluctuations. Motions along fixed axes were measured as shown in Figure 5. No distinction between different parts of the bladder could be seen in terms of the nature of surface movements. Within the filmed surface, frequencies of micromotions in different areas were not exactly the same and two areas could show coincident contractions in phase at some point in time, but be out of phase at another time, i.e. traces (2) and (3) in Figure 5. The correspondence between micromotions and whole bladder pressure fluctuations was variable. At one extreme, large contractions in localized areas could generate obvious pressure fluctuations as exemplified in traces (2) and (3) at $20 \mathrm{~s}$ in Figure 5. However, at the other extreme pressure fluctuations could be absent despite clear contractions as can be seen in traces (1), (3), and (4) at $110 \mathrm{~s}$. We summise that this variation in pressure reflects the summation of all movements of the bladder surface, contractile, or relaxing, visible to our camera or not.

\section{DISCUSSION}

The primary aims of the project were to ascertain the viability of a large perfused bladder, demonstrate in principle drug administration by different routes, and quantify micromotion filming and its relation to fluctuations of intravesical pressure. The pig bladder is a useful practical alternative to human bladder for elucidating physiological principles of potential clinical relevance. We were able to confirm organ viability using histological, biochemical, and pharmacological parameters, and maintain physiological conditions for a sufficient time to make detailed observations on intravesical pressure and bladder wall movement.
With large animal whole organ preparations, there is a balance to be struck when determining the rate of tissue perfusion. Adequate oxygenation must be ensured, but care has to be taken as high rates of perfusion will lead to increasing tissue edema as a result of elevated hydrostatic pressures. The molecular diffusion distance is approximately $100-200 \mu \mathrm{m}$ from a supplying capillary (Colton, 1995) and consequently excessive edema will negatively impact on the delivery of oxygen and nutrients at a cellular level. The rate of pump perfusion was therefore optimized by measuring bladder weights before and after the experimental period and adjusted according to the degree of edema that developed. Despite this, a small amount of tissue edema was inevitable as the Kreb's solution used for perfusion lacks colloid oncotic pressure. This effect could be reduced by the addition of albumin/Dextran, but it was important to establish the proof of principle that viability could be maintained before proceeding with more expensive experimental protocols.

Changes in intra-arterial pressure occurred despite a constant pump perfusion rate and these mirrored the changes to intravesical pressure. This demonstrates that intravascular resistance is directly related to bladder wall tension, as has been reported in vivo (Greenland and Brading, 2001). This is further evidenced by decreases in mean bladder blood flow seen in human detrusor muscle during bladder filling as measured using laser Doppler flow (Batista et al., 1996). Reassuringly, none of the experimental bladders exhibited marked and persistent increases in perfusion pressure (irrespective of bladder volume) as this has previously been shown to be indicative of reducing isolated organ viability (Belzer et al., 1968).

Arterial administration of drugs elicited consistent dosedependent responses and consequently, we have established the potential of arterial administration to an isolated bladder model, as well as via serosal and vesical routes typically used in other isolated bladder models such as rodent and rabbit (Chun et al., 1996; Matsumoto et al., 2002). The scientific interest of route of drug administration results from an interpretation of their likely influences. The arterial route is likely to achieve direct exposure of the entire bladder wall, given the extensive vascular supply to the musculature and suburothelial space. All interacting cell types are thus likely to be influenced synchronously, giving a useful insight into integrative bladder physiology. The serosal route might achieve this in a thin-walled bladder, but limitations of diffusion would prevent it in a bladder wall as thick as a pig or human. The vesical route necessarily exposes the urothelium as the first point of contact, with other tissues being exposed subsequently, and only if the agent can diffuse through the urothelial barrier. If it is unable to cross the urothelium, any influence on contractile activity must be an indirect consequence of mediator release from the urothelium. This raises the possibility of evaluation of urothelial function by stimulating its urothelial surface and comparing responses with those elicited via the arterial route, and potentially using arterially administered drugs to elaborate on the nature of urothelial mediators released. The maximum contractile response to arterially administered potassium was substantially smaller than that for carbachol - a difference which is also apparent in isolated detrusor muscle strips (Mills et al., 2000a). When given intravesically, potassium elicited no contraction; we presume this indicates intact urothelial barrier function, and may be pertinent for designing 

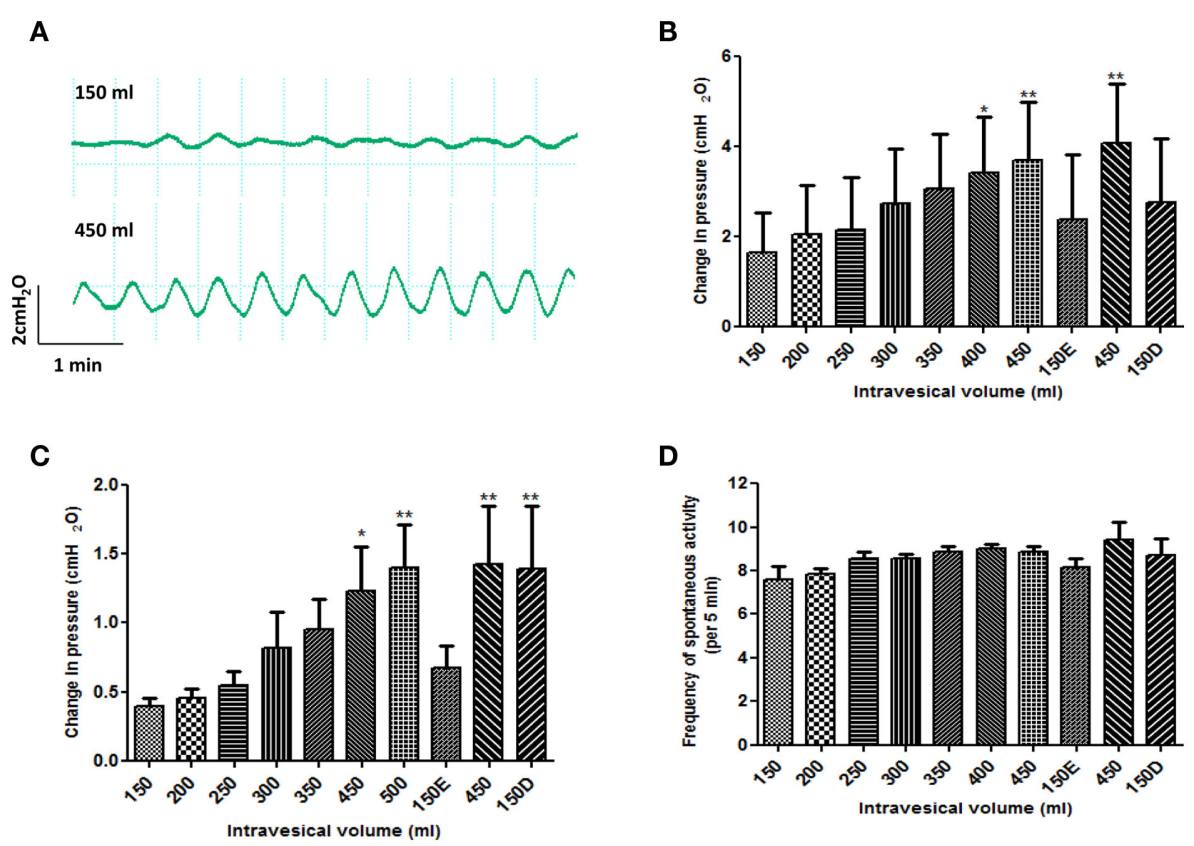

FIGURE 4 | Effect of changes to intravesical bladder volume on spontaneous contractions of isolated pig bladder. (A) spontaneous contractions generated at low $(150 \mathrm{ml})$ versus high $(450 \mathrm{ml})$ bladder volumes. (B) base-line intravesical pressure (C) amplitude of spontaneous contractions and (D) frequency of spontaneous

contractions. After filling to $450 \mathrm{ml}$, a comparison was also made between bladders that were emptied and refilled with $150 \mathrm{ml}$ of fresh Krebs (150E) versus bladders drained down to $150 \mathrm{ml}(150 \mathrm{D}) .{ }^{*} p<0.05$ and ${ }^{* *} p<0.01$ versus the initial $150 \mathrm{ml}$ intravesical volume. Data are presented as mean \pm SEM.

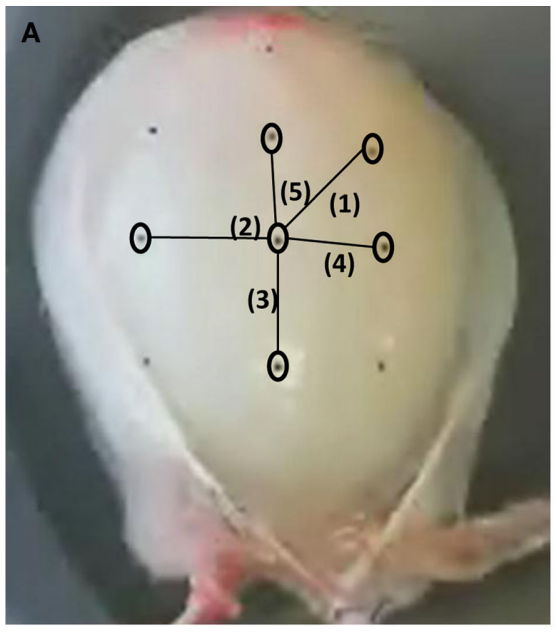

FIGURE 5 | Assessment of bladder wall movements using carbon particles applied to the serosal surface of the bladder as optical markers: (A) demonstrates a photograph of a bladder showing the position of six particles and five consequent axes labeled (1) to (5) and their correlation

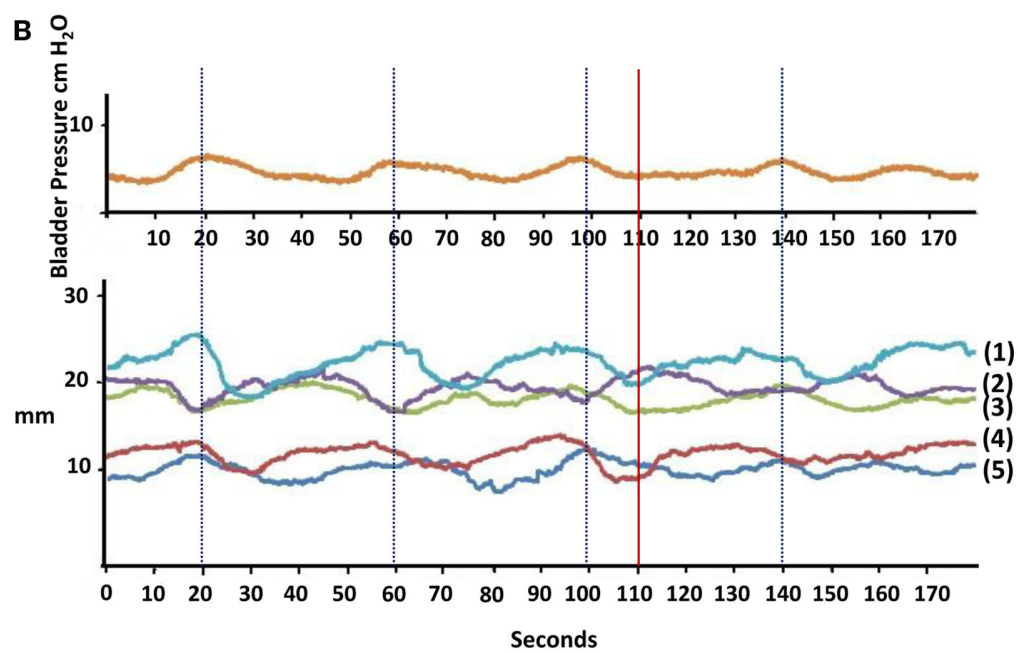

to $(B)$ intravesical pressure fluctuations at $\mathbf{1 5 0} \mathbf{m l}$. The graph shows changes in distance between pairs of carbon particles over a 3-min period for the five axes. The downward deflections represent shortening/contraction along the axis whilst the upward deflections represent elongation/relaxation. experimental approaches to evaluate bladder pain syndrome, for which inappropriate urothelial permeability to potassium could be a mechanistic contributor (Parsons, 2011).

Different protocols were employed for the two routes of administration. Because arterial perfusion was continuous, drugs were introduced as boluses into the perfusate. Thus, the duration of exposure was determined by the perfusion rate, the rate of distribution through tissue, and the rate of washout. By contrast, the vesical route required controlled, slow drug instillation, and a more prolonged dwell-time, aiming for mixing with 
minimal disturbance, as the inevitable alteration of bladder volume is a confounding factor for interpretation. Thus, it was not possible to achieve equivalent dose exposure and timing of onset to enable direct comparison between the two routes of administration.

The bladder wall movements are in keeping with a previous observational study in pigs, which demonstrated an increase in amplitude of phasic contractions with no change in frequency in response to bladder filling (Coolsaet et al., 1993); in rodents, both amplitude and frequency increase with bladder filling (Drake et al., 2003b; Lagou et al., 2004). The enhanced pressure fluctuations associated with filling might reflect a change in length-tension relationship of the bladder wall, stretch-activated myogenic responses, or local reflex activity (Lagou et al., 2004). It would also be interesting to evaluate whether the calcium changes mapped in rodent urothelium (Kanai et al., 2011) can be linked to the movements we have observed. We also evaluated any link between specific movements of the bladder wall to particular fluctuations in the pressure trace. This is difficult to achieve, as changes in intravesical pressure will be the result of the summation of all bladder wall movements, not solely from the proportion of the bladder surface being filmed. This is evidenced by the fact that on occasions, no obvious pressure changes were detected despite apparently substantial movements in the bladder wall. This is likely to be clinically relevant as the presence of exaggerated bladder wall movements without objective urodynamic pressure changes has been demonstrated in women with increased filling sensation (Drake et al., 2005).

Alongside the physiological relevance, the model described implicitly could be extrapolated to evaluate pathophysiology. Akin to approaches used in rodents, intravesical exposure to topical irritants or urothelial permeabilization could be evaluated in the isolated pig bladder. Bladder outlet obstruction in the pig has been

\section{REFERENCES}

Batista, J. E., Wagner, J. R., Azadzoi, K. M., Krane, R. J., and Siroky, M. B. (1996). Direct measurement of blood flow in the human bladder. $J$. Urol. 155, 630-633.

Belzer, F. O., Ashby, B. S., Huang, J. S., and Dunphy, J. E. (1968). Etiology of rising perfusion pressure in isolated organ perfusion. Ann. Surg. 168, 382-391.

Buckner, S. A., Milicic, I., Daza, A. V., Coghlan, M. J., and Gopalakrishnan, M. (2002). Spontaneous phasic activity of the pig urinary bladder smooth muscle: characteristics and sensitivity to potassium channel modulators. Br. J. Pharmacol. 135, 639-648.

Buyuknacar, H. S., Gocmen, C., De Groat, W. C., Kumcu, E. K., Wu, H. Y., and Onder, S. (2010). Differential effect of L-cysteine in isolated whole-bladder preparations from neonatal and adult rats. J. Pharmacol. Exp. Ther. 333, 228-235.
Chun, A., Bertelsen, D. L., Murphy, J., Kau, S., and Levin, R. M. (1996). Comparative effects of intravesical versus extravesical administration of ZD6169 and cromakalim on the response of the in vitro rat whole bladder to field stimulation. Pharmacology 52, 347-352.

Colton, C. K. (1995). Implantable biohybrid artificial organs. Cell Transplant. 4, 415-436.

Coolsaet, B. L., Van Duyl, W. A., Van Os-Bossagh, P., and De Bakker, $\mathrm{H}$. V. (1993). New concepts in relation to urge and detrusor activity. Neurourol. Urodyn. 12, 463-471.

Crowe, R., and Burnstock, G. (1989). A histochemical and immunohistochemical study of the autonomic innervation of the lower urinary tract of the female pig. Is the pig a good model for the human bladder and urethra? J. Urol. 141, 414-422.

Dittrich, R., Beckmann, M. W., Maake, C., Oppelt, P. G., Mueller, A., Mueller, S., Hoffmann, I., Naumann, G.,

used as a means of generating detrusor overactivity, as described by Greenland and Brading (2001), and the current approach could be employed to supplement urodynamic data in such a model.

Our study differs from the previous report on isolated whole pig bladder experiments (Dittrich et al., 2007) in several aspects. The current study sought to establish both histological and pharmacological viability of the isolated perfused bladder. We used isovolumetric conditions, and were thereby able to examine the effects of alterations of bladder volume on physiological parameters. We also tracked bladder wall movements. The limitation of the technique is the unavoidable warm ischemia time between the death of the animal and retrieval of its bladder. This appears to have had little effect on the reproducible behavior of the bladders, or their histological and biochemical viability. Nonetheless, in aiming to study function of metabolically active cells, the need must be to minimize warm ischemia time.

In conclusion, this technique gives a valuable insight into the physiology of the large animal bladder which is likely to be more informative than rodent models as a means of gaining insight into clinical conditions such as overactive bladder and detrusor underactivity.

It confirms that large animal bladders can remain viable when perfused in vitro, and gives new experimental potential for elucidating the functional complexities of the integrative physiology of the bladder.

\section{ACKNOWLEDGMENTS}

We gratefully acknowledge the Urology Foundation, The University of the West of England and North Bristol NHS Trust for providing us with the support and funding for this project. The staff at the Langford Abattoir were very accommodating and we thank them for the considerable help they gave us.

Koelbl, H., and Maltaris, T. (2007). The extracorporeal perfusion of the female pig detrusor as an experimental model for the study of bladder contractility. Neurourol. Urodyn. 26, 1024-1029.

Dixon, J. S., and Gosling, J. A. (1983). Histology and fine structure of the muscularis mucosae of the human urinary bladder. J. Anat. 136, 265-271.

Drake, M. J., Harvey, I. J., and Gillespie, J. I. (2003a). Autonomous activity in the isolated guinea pig bladder. Exp. Physiol. 88, 19-30.

Drake, M. J., Hedlund, P., Harvey, I. J., Pandita, R. K., Andersson, K. E., and Gillespie, J. I. (2003b). Partial outlet obstruction enhances modular autonomous activity in the isolated rat bladder. J. Urol. 170, 276-279.

Drake, M. J., Harvey, I. J., Gillespie, J. I., and Van Duyl, W. A. (2005). Localized contractions in the normal human bladder and in urinary urgency. BJU Int. 95, 1002-1005.
Fabiyi, A. C., and Brading, A. F. (2006). The use of the isolated mouse whole bladder for investigating bladder overactivity. J. Pharmacol. Exp. Ther. 319, 1386-1394.

Gevaert, T., Owsianik, G., Hutchings, G., Van Leuven, L., Everaerts, W., Nilius, B., and De Ridder, D. (2009). The loss and progressive recovery of voiding after spinal cord interruption in rats is associated with simultaneous changes in autonomous contractile bladder activity. Eur. Urol. 56, 168-176.

Gillespie, J. I., Harvey, I. J., and Drake, M. J. (2003). Agonist- and nerveinduced phasic activity in the isolated whole bladder of the guinea pig: evidence for two types of bladder activity. Exp. Physiol. 88, 343-357.

Greenland, J. E., and Brading, A. F. (2001). The effect of bladder outflow obstruction on detrusor blood flow changes during the voiding cycle in conscious pigs. J. Urol. 165, 245-248. 
Hashitani, H., Fukuta, H., Takano, H., Klemm, M. F., and Suzuki, H. (2001). Origin and propagation of spontaneous excitation in smooth muscle of the guinea-pig urinary bladder. J. Physiol. (Lond.) 530, 273-286.

Kanai, A., Vabbarova, I., Ikeda, Y., Yoshimura, N., Birder, L., HannaMitchell, A., and de Groat, W. (2011). Sophisticated models and methods for studying neurogenic bladder dysfunction. Neurourol. Urodyn. 30, 658-667.

Kershen, R. T., Azadzoi, K. M., and Siroky, M. B. (2002). Blood flow, pressure and compliance in the male human bladder. J. Urol. 168, 121-125.

Kinder, R. B., and Mundy, A. R. (1987). Pathophysiology of idiopathic detrusor instability and detrusor hyper-reflexia. An in vitro study of human detrusor muscle. $\mathrm{Br}$. J. Urol. 60, 509-515.

Lagou, M., Drake, M. J., and Gillespie, J. I. (2004). Volume-induced effects on the isolated bladder: a possible local reflex. BJU Int. 94, 1356-1365.

Matsumoto, S., Chichester, P., Bratslavsky, G., Kogan, B. A., and Levin, R. M. (2002). The functional and structural response to distention of the rabbit whole bladder in vitro. $J$. Urol. 168, 2677-2681.

Mills, I. W., Greenland, J. E., McMurray, G., McCoy, R., Ho, K. M. T., Noble, J. G., and Brading, A. F. (2000a). Studies of the pathophysiology of idiopathic detrusor instability: the physiological properties of the detrusor smooth msucle and its innervation. J. Urol. 163, 646-651.

Mills, I. W., Noble, J. G., and Brading, A. F. (2000b). Radiotelemetered cystometry in pigs: validation and comparison of natural filling versus diuresis cystometry. J. Urol. 164, 1745-1750.

Moore, J. A., and Brading, A. F. (2007). A porcine model of bladder outlet obstruction incorporating radiotelemetered cystometry. BJU Int. 100, 1192-1193.

Oh, S. J., Ahn, S. C., Kim, S. J., Kim, K. W., Lee, A., Kim, K. M., and Choi, H. (1999). Carbacholinduced sustained tonic contraction of rat detrusor muscle. BJU Int. 84, 343-349.

Parsons, C. L. (2011). The role of a leaky urothelium and potassium in the generation of bladder symptoms in interstitial cystitis/overactive bladder, urethral syndrome, prostatitis and gynaecological chronic pelvic pain. BJU Int. 107, 370-375.

Sibley, G. N. (1984). A comparison of spontaneous and nerve-mediated activity in bladder muscle from man, pig and rabbit. J. Physiol. (Lond.) 354, 431-443.

Sibley, G. N. (1985). An experimental model of detrusor instability in the obstructed pig. Br. J. Urol. 57, 292-298.

Sugaya, K., and de Groat, W. C. (2000). Influence of temperature on activity of the isolated whole bladder preparation of neonatal and adult rats. Am. J. Physiol. Regul. Integr. Comp. Physiol. 278, R238-R246.

Teufl, F., Dammann, F., and Wehrmann, M. (1997). In vitro study of morphology of the bladder wall using MR tomography at 1.0 Tesla: correlation with histology. Rofo 166 , 406-410.

Van Duyl, W. A. (1985). Spontaneous contractions in urinary bladder smooth muscle: preliminary results. Neurourol. Urodyn. 4, 301-307.

Yamanishi, T., Chapple, C. R., Yasuda K., and Chess-Williams, R. (2000) The role of $\mathrm{M}(2)$-muscarinic receptors in mediating contraction of the pig urinary bladder in vitro. $\mathrm{Br}$. $J$. Pharmacol. 131, 1482-1488.

Conflict of Interest Statement: The authors declare that the research was conducted in the absence of any commercial or financial relationships that could be construed as a potential conflict of interest.

Received: 18 January 2012; paperpending published: 08 February 2012; accepted: 10 March 2012; published online: 30 March 2012.

Citation: Parsons BA, Drake MJ, Gammie A, Fry CH and Vahabi B (2012) The validation of a functional, isolated pig bladder model for physiological experimentation. Front. Pharmacol. 3:52. doi 10.3389/fphar.2012.00052

This article was submitted to Frontiers in Cardiovascular and Smooth Muscle Pharmacology, a specialty of Frontiers in Pharmacology.

Copyright (c) 2012 Parsons, Drake, Gammie, Fry and Vahabi. This is an openaccess article distributed under the terms of the Creative Commons Attribution Non Commercial License, which permits non-commercial use, distribution, and reproduction in other forums, provided the original authors and source are credited. 